Ciência Florestal, Santa Maria, v. 23, n. 1, p. 19-28, jan.-mar., 2013

ISSN 0103-9954

\title{
INFLUENNCIA DO FOGO NO BANCO DE SEMENTES DO SOLO EM FLORESTA ESTACIONAL SEMIDECIDUAL
}

\author{
THE INFLUENCE OF FIRE ON THE SOIL SEED BANK IN SEMIDECIDUOUS FOREST
}

Virgínia Londe de Camargos ${ }^{1}$ Sebastião Venâncio Martins ${ }^{2}$ Guido Assunção Ribeiro ${ }^{3}$ Flávia Maria da Silva Carmo ${ }^{4}$ Alexandre Francisco da Silva $\dagger^{5}$

\begin{abstract}
RESUMO
Este estudo foi realizado no fragmento "Reserva da Biologia", situado na Universidade Federal de Viçosa, Minas Gerais, $\left(20^{\circ} 35^{\prime}-28^{\circ} 50^{\prime} \mathrm{S}\right.$ e $\left.42^{\circ} 45^{\prime}-43^{\circ} 00^{\prime} \mathrm{W}\right)$ onde foram instaladas 10 parcelas de 5 x 5 m interdistantes em $1 \mathrm{~m}$. Foi realizada uma queima controlada nas parcelas instaladas, utilizando a técnica do fogo a favor do vento, obedecendo ao sentido do aclive. O objetivo foi caracterizar o banco de sementes do solo antes e depois do fogo, para verificar os efeitos desse distúrbio na densidade das populações e na composição florística da comunidade vegetal. No centro de cada parcela foi coletada uma amostra de solo de $40 \times 25 \mathrm{~cm}$, a partir da superfície da serapilheira até $5 \mathrm{~cm}$ de profundidade. Um dia após a coleta das amostras de solos as parcelas foram submetidas à queima controlada. Imediatamente após a queima foram realizadas novas coletas de solo seguindo a mesma metodologia adotada anteriormente. Foram obtidas 528 e 429 sementes germinadas das amostras do banco de sementes do solo antes e após o fogo, respectivamente, pertencentes a 23 espécies de 14 famílias botânicas, sendo as mais representativas Melastomataceae, Asteraceae e Urticaceae. Entre as duas amostragens (antes e após o fogo) não houve redução significativa da riqueza de espécies e a similaridade florística foi de $34 \%$. Miconia cinnamomifolia e Leandra purpurascens foram as espécies mais abundantes nas duas amostragens. As espécies pioneiras se destacaram com 44 e $40 \%$ das espécies presentes no banco de sementes antes e após o fogo, respectivamente.
\end{abstract}

Palavras-chave: ecologia do fogo; restauração florestal; distúrbio florestal.

\section{ABSTRACT}

This study was carried out in a fragment called "Reserva da Biologia", which belongs to the Universidade Federal de Viçosa, in Minas Gerais State, Brazil (20 $25^{\circ}$ ' $28^{\circ} 50^{\prime}$ 'S e $42^{\circ} 45^{\prime}-43^{\circ} 00^{\prime} \mathrm{W}$ ), where 10 plots of 5 x 5 $\mathrm{m}$ plots, $1 \mathrm{~m}$ away from each other, were set up. A controlled burning was performed on the plots, following the wind-driven fire technique, according to the slope orientation. The objective was to characterize the soil seed of the tree community before and after fire, in order to verify the effects of such discontinuance on both population density and floristic composition. In the centre of each plot, one $40 \times 25 \mathrm{~cm}$ soil sampling was collected, from the leaf litter downward $5 \mathrm{~cm}$ deep. One day after the soil sampling the plots underwent controlled burning. New soil samplings were done immediately after burning, following the previous methodology. It was counted 528 and 429 seedlings emerging from the soil seed bank before and after the fire, respectively. Such plants were of 23 species and 14 botanical families, from which Melastomataceae, Asteraceae and Urticaceae stood out. There was no meaningful reduction in the species richness or in the density of individuals of the populations between both samplings. The floristic similarity was $34 \%$. Miconia

1. Bióloga, Dra., Analista Ambiental da Veracel Celulose S.A., CEP 45820-970, Eunápolis (BA). virginia.camargos@veracel.com.br

2. Engenheiro Florestal, Dr., Professor Associado do Departamento de Engenharia Florestal, Universidade Federal de Viçosa, CEP 36570-000, Viçosa (MG). venancio@ufv.br

3. Engenheiro Florestal, Dr., Professor Associado do Departamento de Engenharia Florestal, Universidade Federal de Viçosa, CEP 36570-000, Viçosa (MG). gribeiro@ufv.br

4. Bióloga, Dra., Professora Adjunta do Departamento de Biologia Geral, Universidade Federal de Viçosa, CEP 36570-000, Viçosa (MG). fmcarmoufv@gmail.com

5. †Biólogo, Dr., Professor Adjunto IV do Departamento de Biologia Vegetal, Universidade Federal de Viçosa, CEP 36570-000, Viçosa (MG). (in memoriam)

Recebido para publicação em 8/07/2009 e aceito em 7/12/2011

Ci. Fl., v. 23, n. 1, jan.-mar., 2013 
cinnamomifolia and Leandra purpurascens were the most frequent/abundant species. Pioneer species stood out making up 44 and $40 \%$ of the species found in the area before and after fire, respectively.

Keywords: fire ecology; forest restoration; forest disturbance.

\section{INTRODUÇÃO}

A regeneração florestal é definida como o processo pelo qual a floresta perturbada atinge características de floresta madura, o que pressupõe modificações nas características da comunidade e mudanças direcionais na composição de espécies (KLEIN, 1980; SALDARRIAGA e UHL, 1991). Em florestas tropicais, o principal meio de regeneração das espécies dá-se através da chuva de sementes, do banco de sementes do solo, do banco de plântulas e da emissão rápida de brotos e/ou raízes provenientes de indivíduos danificados (GARWOOD, 1989).

Banco de sementes do solo é um termo usado para designar todas as sementes viáveis no solo ou associadas à serapilheira para uma determinada área num dado momento (BASKIN e BASKIN, 1998; FENNER e THOMPSON, 2005). Em florestas tropicais, está envolvido no estabelecimento de populações e de grupos ecológicos, na manutenção da diversidade de espécies, e na restauração da riqueza de espécies durante a regeneração após distúrbios naturais ou antrópicos, como o fogo (UHL et al., 1988; GARWOOD, 1989; SIMPSON et al., 1989; MARTINS et al., 2008; MARTINS, 2009).

As respostas das plantas aos impactos do fogo variam conforme a intensidade, a frequência e a duração dos incêndios e também à formação vegetal atingida. Em algumas formações, como o cerrado, várias espécies resistem à ocorrência do fogo ou são até mesmo favorecidas por ele, uma vez que as altas temperaturas ajudam na quebra de dormência (COUTINHO, 1978, 1990; OLIVEIRAFILHO e RATTER, 2002).

A restauração da vegetação pelas sementes presentes no banco de sementes do solo, em ambiente perturbado por fogo, atua como um fator regulador da velocidade da regeneração em florestas tropicais (UHL, 1987; GARWOOD, 1989). Mas este potencial de regeneração pode ser diretamente afetado pela intensidade e frequência de ocorrência do fogo (WRIGHT e BAILEY, 1982; KENNARD et al., 2002).

A dormência representa o mecanismo principal de preservação de espécies no banco de sementes, propiciando a germinação ao longo dos anos e garantindo a sobrevivência dos indivíduos na forma de sementes, sob condições adversas, até mesmo quando a população de plantas é completamente eliminada (CARMONA, 1992).

Alguns estudos sobre os efeitos do fogo em banco de sementes do solo vêm sendo desenvolvidos em ecossistemas mediterrâneos (FERRANDIS et al., 1999; FERRANDIS e HERRANZ, 2001; WILLIANS et al., 2005). Estes estudos mostram redução na densidade de sementes no banco do solo imediatamente após o fogo, e um ano após o distúrbio. Em florestas tropicais alguns estudos têm mostrado que as mudanças na diversidade de espécies e densidade de indivíduos variam de acordo com a severidade do distúrbio (UHL et al., 1982; PUTZ, 1983; UHL, 1987). Em florestas estacionais semideciduais, tem sido demonstrado alterações na composição florística e estrutura do estrato de regeneração após incêndios florestais (CASTELLANI e STUBBLEBINE, 1993; MARTINS et al., 2002; RODRIGUES et al., 2005; SILVA et al., 2005). Embora o tema seja relevante, são poucos os estudos desenvolvidos sobre o assunto e raras são as pesquisas sobre os efeitos do fogo em banco de sementes do solo nessas formações florestais (MAROD et al., 2002; MELO et al., 2007). O principal resultado dessas pesquisas é a marcante perda de riqueza de espécies e de densidade das populações presentes nas comunidades submetidas ao fogo.

Neste contexto, o objetivo deste estudo foi caracterizar e avaliar os efeitos do fogo sobre o banco de sementes do solo de um trecho de Floresta Estacional Semidecidual e suas consequências na densidade das populações e na composição florística das espécies da comunidade.

\section{MATERIAL E MÉTODO}

\section{Caracterização da área de estudo}

$\mathrm{O}$ estudo foi realizado em um fragmento bem preservado de Floresta Estacional Semidecidual Montana, (VELOSO et al., 1991), em regeneração natural há 80 anos, conhecido como "Reserva da Biologia", situado no campus da Universidade 
Federal de Viçosa, no município de Viçosa, MG $\left(20^{\circ} 35^{\prime}-28^{\circ} 50^{\prime} \mathrm{S}\right.$ e $\left.42^{\circ} 45^{\prime}-43^{\circ} 00^{\prime} \mathrm{W}\right)$. A área total do fragmento é de 75 ha, com altitude variando entre 725 a $745 \mathrm{~m}$. O relevo possui características montanhosas, com predominância de solos tipo Latossolo Vermelho-Amarelo Álico, nos topos dos morros e encostas e Podzólico Vermelho-Amarelo Câmbico, nos terraços (CORREA, 1984).

O Clima, segundo a classificação de Köppen, é do tipo $\mathrm{Cw}_{b}$, subtropical moderado úmido. A precipitação anual está em entorno de 1.314 mm (CASTRO et al., 1983).

\section{Amostragem}

Em um trecho de encosta do fragmento florestal, próximo da borda, e com face de exposição solar oeste-sudeste foram instaladas 10 parcelas de 5 x $5 \mathrm{~m}$ interdistantes em $1 \mathrm{~m}$, formando uma faixa vertical, perfazendo um total de $250 \mathrm{~m}^{2}$. No entorno das parcelas foram construídos aceiros de $1 \mathrm{~m}$ de largura para evitar que o fogo passasse para a área externa do local do tratamento. A duração do fogo foi de 2 horas, entre sua ignição na primeira parcela e extinção na última.

Para caracterizar o banco de sementes do solo do local foi coletada uma amostra de solo de $40 \mathrm{x}$ $25 \mathrm{~cm}$ no centro de cada parcela, após a retirada da serapilheira, até $5 \mathrm{~cm}$ de profundidade. As amostras de solo foram coletadas de forma a preservar sua estrutura, mantendo-as em blocos sem destorroar e foram etiquetadas e condicionadas individualmente.

Um dia após a coleta das amostras de solo, cada parcela foi submetida à queima controlada utilizando a técnica do fogo a favor do vento. Obedecendo ao sentido do aclive, a linha de fogo foi acesa na parcela situada no extremo oposto ao topo do morro, com o auxílio de um "pinga-fogo". A queima foi realizada dia 05 de setembro de 2005, iniciada às $09 \mathrm{~h} 30 \mathrm{~min}$ da manhã com duração total de 2 horas entre ignição e extinção total.

Para avaliar o banco de sementes do solo, após a queima da vegetação foi novamente coletada uma amostra do solo, no centro de cada uma das 10 parcelas de $5 \times 5 \mathrm{~m}$, seguindo a mesma metodologia empregada antes da queima.

As amostras de solo de ambas as fases (antes e após o fogo) foram transferidas para bandejas previamente furadas para permitir a drenagem, devidamente etiquetadas e transportadas para a casa de vegetação de tela tipo sombrite preta, localizada no Horto Botânico da Universidade Federal de Viçosa - UFV, onde foram depositadas em bancada suspensa a $1 \mathrm{~m}$ de altura em relação ao nível do solo. O solo contido nas bandejas foi regado diariamente para manutenção das condições de umidades adequadas à germinação das sementes.

A avaliação das amostras do banco de sementes do solo, tanto antes quanto após o fogo, foi feita por contagem das plantas germinadas mensalmente, de setembro de 2005 a setembro de 2007, retirando-se das bandejas os indivíduos já identificados. As plantas com dificuldade de identificação foram transplantadas para sacos de crescimento de mudas e mantidas na casa de vegetação até a identificação. A identificação das espécies foi realizada por meio de consultas à literatura específica, por comparação com exsicatas depositadas no herbário da UFV e com o auxílio de pesquisadores especialistas em sistemática taxonômica. Para a classificação taxonômica, foi adotado o sistema APG III - Angiosperm Phylogeny Group (APG III, 2009).

As espécies identificadas no banco de sementes, antes e após o fogo, foram classificadas de acordo com a metodologia de Budowski (1965) adaptada por Gandolfi et al. (1995) quanto ao grupo ecológico em pioneiras, secundárias iniciais e secundárias tardias; quanto ao habitat em plantas de sub-bosque (GANDOLFI et al., 1995; GANDOLFI, 2000; PAULA et al., 2002; PIVELLO et al., 2006) quanto às formas de vida em herbácea, arbustiva ou arbórea (CASTELLANI e STUBBLEBINE, 1993; MARTINS et al., 2002, 2008; MELO et al., 2007) e quanto à síndrome de dispersão em anemocórica, autocórica ou zoocórica (VAN DER PIJL, 1982; CASTELLANI e STUBBLEBINE, 1993; PIVELLO et al., 2006).

A partir dos dados obtidos, foram calculadas a densidade e a frequência relativas de cada espécie, bem como o índice de similaridade de Jaccard (J) entre a composição de espécies obtida no banco de sementes antes e após o fogo (MUELLERDOMBOIS e ELLENBERG, 1974). Através de analise de variância foi comparada a germinação total, ou seja, das sementes germinadas de todas as espécies, antes e após o tratamento com fogo. A mesma análise foi aplicada para comparar a germinação antes e após o fogo das cinco espécies mais abundantes nestas duas condições.

\section{RESULTADOS E DISCUSSÃO}

Ocorreu uma redução no número total de sementes germinadas do banco de sementes do 
solo após o tratamento com fogo, passando de 528 sementes antes do fogo para 429 sementes pósfogo, o que resultou numa redução da densidade de sementes germinadas de 1056 para 858 sementes/ $\mathrm{m}^{2}$, respectivamente, o que equivale a uma redução na germinação de $18,75 \%$ após o tratamento com fogo.

Esses valores de densidade do banco de sementes, tanto antes como após o fogo, são intermediários aos valores indicados por Garwood (1989) para florestas tropicais secundárias e primárias, de 1650 sementes $/ \mathrm{m}^{2}$ e 380 sementes $/ \mathrm{m}^{2}$, respectivamente. E o valor de densidade após o fogo é muito semelhante ao valor de 857,6 sementes/ $\mathrm{m}^{2}$ estimado em floresta secundária em área de mineração na Zona da Mata mineira, (MARTINS et al., 2008) e ao valor de 872 sementes $/ \mathrm{m}^{2}$ em trecho de Floresta Atlântica no Parque Estadual de Intervales, SP (BAIDER et al., 1999). Portanto, o impacto do fogo na redução da densidade do banco de sementes do solo do trecho de floresta estudado não interferiu no potencial deste mecanismo na regeneração florestal.

Logo após a coleta das amostras de solo superficial, as primeiras germinações de sementes ocorreram após o fogo, sendo de espécies da família Melastomataceae, que apareceram tanto antes quanto após o tratamento, mas com germinação mais rápida após o fogo. Este resultado indica que o tratamento com fogo acelerou a germinação destas espécies através da quebra de dormência. Algumas espécies do banco necessitam apenas de uma ruptura da camada de serapilheira para germinarem, enquanto que outras precisam de um distúrbio no solo, simultaneamente à abertura do dossel (METCALFE e TURNER, 1998). Araújo et al. (2001) observaram uma maior proporção de sementes germinadas no primeiro mês de acompanhamento, resultante da exposição das sementes à luz e da maior amplitude térmica. Nestes casos as sementes apresentam dormência fisiológica, pois o embrião está completamente desenvolvido, porém, não recebe condições propícias, como água, temperatura e luz adequadas para iniciar a germinação (BASKIN e BASKIN, 1998).

Do total de plantas germinadas antes e após o fogo, foram identificadas 23 espécies pertencentes a 14 famílias botânicas. Além dessas, três espécies não foram identificadas, permanecendo como morfoespécies e uma espécie foi identificada somente em nível de família.
Considerando as duas amostragens separadamente, antes do fogo foram identificadas 16 espécies distribuídas em 13 gêneros e nove famílias, permanecendo duas espécies não identificadas e uma somente em nível de família, onde se destacou Melastomataceae com três espécies (Tabela 1). Na amostragem após o fogo, foram identificadas 15 espécies distribuídas em 13 gêneros de 11 famílias, permanecendo uma espécie não identificada.

Do total de espécies encontradas, oito foram comuns às duas amostragens. No banco de sementes antes do fogo foram encontradas oito espécies exclusivas, não havendo predominância de nenhum grupo ecológico entre elas. Após o fogo foram amostradas sete espécies exclusivas. $\mathrm{O}$ índice de Jaccard (J) obtido foi de $34 \%$, indicando alta similaridade de espécies entre as duas amostragens, uma vez que, segundo MuellerDombois e Ellenberg (1974), quando o valor desse índice é superior a $25 \%$, as duas amostras comparadas são consideradas floristicamente semelhantes.

Nos dois tratamentos ocorreu predominância de espécies arbóreas, com 7 espécies germinadas no banco antes do fogo $(43,75 \%$ do total de espécies), as quais contribuíram com 350 indivíduos $(66,3 \%$ do total de sementes germinadas). Após o fogo foram amostradas no banco 8 espécies arbóreas (53,3\% do total), que contribuíram com 262 indivíduos $(61,1 \%$ do total). As espécies arbóreas pioneiras foram predominantes no banco de sementes do solo nas duas amostragens com 44 e $40 \%$ das espécies antes e após o fogo, respectivamente. As espécies amostradas no sub-bosque vieram em seguida com $19 \%$ das espécies antes do fogo e $27 \%$ das espécies após o fogo (Figura 1). Entre estas espécies Rubus rosifolius e Ruellia subsessilis, são secundárias tardias que crescem à sombra do dossel, já Conyza primulifolia, Relbunium microphyllum e Sida rhombifolia são ruderais de áreas perturbadas que estão presentes neste habitat de sub-bosque devido à área do estudo estar situada na borda do fragmento e, portanto, próxima de áreas antropizadas como terrenos e campos agrícolas abandonados.

Das 23 espécies identificadas no total das amostragens, seis eram herbáceas, dentre elas apenas Solanum americanum apresentou um número de indivíduos representativo (21). As demais estavam presentes na amostra com apenas um ou poucos indivíduos. 
TABELA 1: Número de espécies amostradas no banco de sementes do solo antes e após tratamento com fogo em um fragmento de Floresta Estacional Semidecidual, Viçosa, MG.

TABLE 1: Sampled species in the soil seed bank before and after fire treatment in a semideciduous forest fragment, Viçosa, MG state.

\begin{tabular}{l}
\hline Famílias e espécies \\
\hline
\end{tabular}

\begin{tabular}{|c|c|c|c|c|c|c|c|c|}
\hline Relbunium microphyllum (A. Gray) Hemsl. & SB & & $\mathrm{H}$ & Zoo & - & 3 & - & 20 \\
\hline \multicolumn{9}{|c|}{ SOLANACEAE } \\
\hline Solanum americanum Mill. & & $\mathrm{P}$ & $\mathrm{H}$ & Zoo & 21 & 3 & 30 & 10 \\
\hline
\end{tabular}

Cecropia glaziovi Snethl.

Cecropia hololeuca Miq.

Morfoespécie 1

Morfoespécie 2

Morfoespécie 3

Total

\begin{tabular}{r|c|c|c|c|c|c}
$\mathrm{P}$ & $\mathrm{A}$ & $\mathrm{Zoo}$ & 7 & 5 & 10 & 20 \\
\hline $\mathrm{P}$ & $\mathrm{A}$ & $\mathrm{Zoo}$ & 11 & - & 40 & - \\
\hline $\mathrm{SC}$ & $\mathrm{SC}$ & $\mathrm{SC}$ & 2 & - & 10 & - \\
\hline $\mathrm{SC}$ & $\mathrm{SC}$ & $\mathrm{SC}$ & 4 & - & 20 & - \\
\hline $\mathrm{SC}$ & $\mathrm{SC}$ & $\mathrm{SC}$ & - & 4 & 20 & - \\
\hline & & & 528 & 429 & 100 & 100 \\
\hline
\end{tabular}

Em que: $\mathrm{GE}=$ grupo ecológico $(\mathrm{P}=$ pioneira, $\mathrm{SI}=$ secundária inicial, $\mathrm{ST}=$ secundária tardia, $\mathrm{SC}=$ não classificada $)$, $\mathrm{HB}=$ Habitat de amostragem, $\mathrm{SB}=$ sub-bosque, $\mathrm{FV}=$ forma de vida $(\mathrm{A}=$ árvore, $\mathrm{Arb}=$ arbusto, $\mathrm{H}=$ erva $), \mathrm{SD}=$ síndrome de dispersão $(\mathrm{Ane}=$ anemocórica, $\mathrm{Aut}=$ autocórica, $\mathrm{Zoo}=$ zoocórica), $\mathrm{AF}=$ antes do fogo, $\mathrm{PF}=$ pós-fogo. 


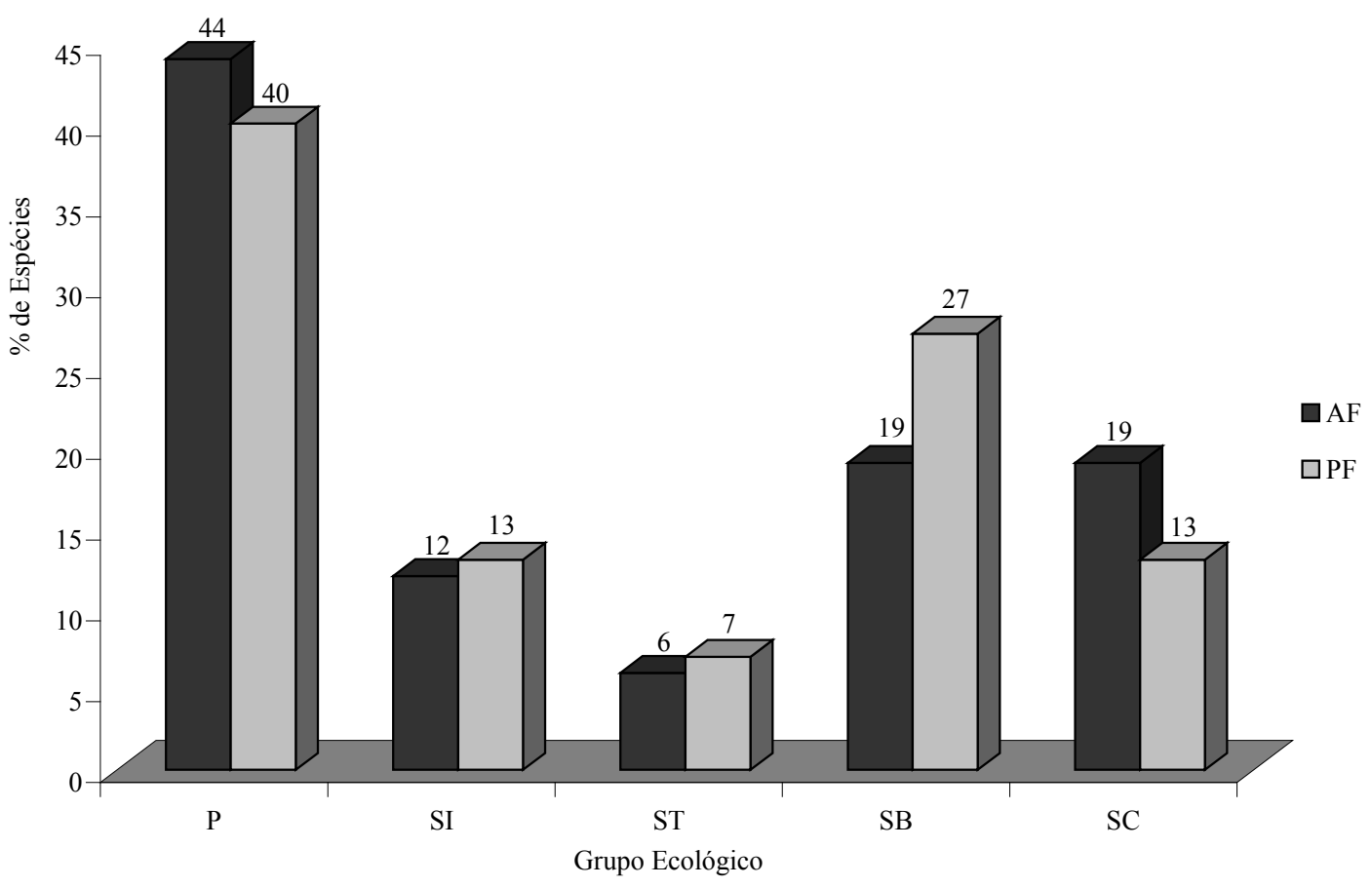

Sendo: $\mathrm{AF}=$ antes do fogo $\mathrm{PF}=$ após o fogo; $\mathrm{P}=$ pioneiras; $\mathrm{SI}=$ secundárias iniciais; $\mathrm{ST}=$ secundárias tardias, $\mathrm{SB}=$ sub-bosque; $\mathrm{SC}=$ sem classificação.

FIGURA 1: Porcentagem de espécies observadas no banco de sementes do solo de em fragmento de Floresta Estacional Semidecidual em Viçosa, MG, de acordo com o grupo ecológico.

FIGURE 1: Soil seed bank species percentage for ecological group in a Semideciduous Forest fragment in Viçosa, MG state.

As espécies arbustivas somaram $31,4 \%$ do total de indivíduos obtidos nas duas amostragens, sendo que somente Leandra purpurascens contribuiu com 216 plantas, e Piper gaudichaudianum, com 20.

A proporção entre espécies arbóreas, arbustivas e herbáceas no banco de sementes do solo tem sido utilizada como indicador do potencial de regeneração de ecossistemas florestais, sendo a maior riqueza e densidade de espécies herbáceas um indicador de fragilidade do ecossistema frente a distúrbios severos, ao passo que maiores riquezas e densidades de espécies arbóreas indicam uma boa resiliência da floresta (HOPKINS et al., 1990; MARTINS et al., 2008; MARTINS, 2009). Dessa maneira, estes resultados permitem interpretar que o trecho de floresta estudado possui um abundante banco de sementes, rico em espécies arbóreas e pioneiras que tendem a garantir a sua regeneração caso ocorra uma perturbação severa como o fogo, o que ficou demonstrado também pela manutenção deste banco após o fogo experimental.

Entre as espécies arbóreas, Miconia cinnamomifolia foi a mais abundante, representada por 297 indivíduos antes do fogo e 232 após o fogo, somando $88 \%$ do total de indivíduos arbóreos observados nas duas amostragens. Considerando apenas as cinco espécies mais abundantes, Miconia cinnamomifolia e Leandra purpurascens, outra Melastomataceae, ocorreram em todas as amostras e, juntas, somaram $77,8 \%$ do total de sementes germinadas, antes e após o fogo, seguidas por Piper gaudichaudianum, com $5 \%$ do total de sementes germinadas, Sorocea bomplandii, com $4 \%$ e Solanum americanum, com $3 \%$.

Miconia cinnamomifolia produz grande quantidade de sementes (LORENZI, 2000), estando presente na vegetação adulta nas proximidades do trecho estudado, o que pode ter favorecido sua dominância no banco e demonstra sua importância na regeneração desta floresta. A família Melastomataceae tem sido amostrada com elevada densidade no banco de sementes de florestas tropicais, sendo importante na regeneração destas florestas (DALLING et al., 1998; BAIDER et al., 1999).

Em dois estudos sobre banco de sementes do solo de fragmentos de Floresta Estacional Semidecidual, muito próximos à área estudada, Souza (2003) e Batista Neto et al. (2007) também 
encontraram Miconia cinnamomifolia como a espécie mais abundante no banco de sementes do solo. Concomitantemente com este estudo, Franco (2005) também encontrou Miconia cinnamomifolia e Leandra purpurascens como as espécies dominantes no banco de sementes do solo em outro fragmento no município de Viçosa, MG. Estes resultados mostram que o banco de sementes persistente definido por Garwood (1989) pode ser dominado por uma ou duas espécies, mesmo quando a maioria das espécies pioneiras produza elevada quantidade de sementes.

Considerando apenas as cinco espécies mais abundantes nas duas amostragens, somente Piper gaudichaudianum e Solanum americanum mostraram diferenças estatisticamente significativas $(\mathrm{P}<0,05)$ de densidade antes e após o fogo. Para Piper gaudichaudianum o número de indivíduos aumentou de 10 para 37 indivíduos após tratamento com fogo, bem como a frequência desta espécie passando de $20 \%$ para $70 \%$ das parcelas após o fogo. Já para Solanum americanum a redução no número de indivíduos foi de 21 para 3 antes e depois do fogo e sua ocorrência foi mais restrita, em 30 e $10 \%$ das parcelas, respectivamente.

O aumento significativo na densidade de Piper gaudichaudianum após o fogo pode estar relacionado com o elevado número de indivíduos da espécie na vegetação adulta neste trecho de floresta (GASPARINI JÚNIOR, 2004). Como a espécie não possui dormência, com sementes germinando tanto em condições de sombra como de luz (CÁCERES et al., 2007), a proximidade de indivíduos adultos é essencial para acrescentar sementes periodicamente ao solo. Segundo Greig (1993), várias espécies do gênero Piper são plantas arbustivas pioneiras e estão envolvidas em processos de regeneração e manutenção da diversidade de florestas, podendo apresentar maior abundância de indivíduos em áreas de borda e interior de clareiras naturais ou antrópicas, pois a luz influencia diretamente a reprodução destas espécies aumentando a quantidade de flores produzidas em uma mesma estação reprodutiva, resultando em aumento na produção de sementes que irá abastecer o estoque no solo.

Assim, o calor do fogo não deve ter sido suficiente para eliminar a viabilidade das pequenas sementes de Piper gaudichaudianum recémdispersas e incorporadas ao solo superficial. Relação contrária ocorreu com as sementes de Solanum americanum em que o fogo deve ter causado grande mortalidade das sementes.
As pioneiras arbóreas Cecropia glaziovi com apenas sete sementes germinadas antes do fogo e Cecropia hololeuca com 11, apresentaram baixa densidade no banco de sementes e, foram ainda, drasticamente reduzidas pelo fogo. O gênero Cecropia tem sido encontrado em vários estudos no banco de sementes em Floresta Estacional Semidecidual (DALLING et al., 1997 e 1998; GROMBONE-GUARATINI e RODRIGUES, 2002; SOUZA, 2003; FRANCO, 2005; BATISTA NETO et al., 2007), sugerindo grande importância para a regeneração dessas florestas, principalmente após grandes distúrbios. Silva-Matos et al. (2005), em estudo de regeneração de Cecropia glaziovi e Trema micrantha, mostraram que as sementes de Cecropia glaziovi são mais sensíveis ao calor moderado, inibindo germinação, concordando com o observado neste estudo onde se observou drástica redução do número de sementes germinadas desta espécie e de Cecropia hololeuca após o tratamento com fogo.

As respostas diferenciadas entre as espécies, algumas com redução na densidade de sementes germinadas pós-fogo e outras até com aumento, indicam que o tempo de duração de duas horas e, por consequência, a intensidade do fogo, pode ter sido letal para determinadas sementes de espécies mais sensíveis e/ou cujas sementes estavam depositadas mais superficialmente no solo, mas indiferente ou até favorávelmente à germinação de sementes mais resistentes e/ou enterradas em maiores profundidades. Neste sentido, Beadle (1940) testou fogos, variando de uma queima superficial de rápida duração (45 minutos) até o fogo de alta intensidade com 8 horas de duração, constatando que o fogo superficial elevou a temperatura do solo a $50{ }^{\circ} \mathrm{C}$, a $2,5 \mathrm{~cm}$ de profundidade, enquanto que o fogo intenso registrou temperaturas próximas a $220^{\circ} \mathrm{C}$, a $7,5 \mathrm{~cm}$ de profundidade.

A zoocoria foi a principal síndrome de dispersão de sementes das espécies amostradas no banco, com 15 espécies, sendo $85 \%$ dos indivíduos zoocóricos pertencentes a espécies pioneiras. A segunda síndrome de dispersão foi a anemocoria, com duas espécies, representando 2,6 \% das sementes germinadas.

O processo de dispersão de sementes é fundamental na regeneração de áreas que sofreram algum tipo de distúrbio, pois através deste processo sementes de plantas pioneiras podem dar início ao processo de sucessão. As espécies pioneiras, em sua maioria, possuem diásporos dispersos por 
frugívoros generalistas como, por exemplo, a família Piperaceae e os gêneros Miconia, Leandra e Cecropia que geralmente são dispersos por aves e Solanum por morcegos frugívoros (VAN DER PIJL, 1982; STILES e ROSSELLI, 1993). Segundo Penhalber e Mantovani (1997), uma elevada porcentagem de sementes de espécies anemocóricas sugere certo grau de perturbação em uma floresta.

O predomínio de espécies zoocóricas no banco de sementes corrobora os estudos de Howe e Smallwood (1982), os quais afirmaram que, em florestas tropicais, 50 a $90 \%$ das sementes de árvores e arbustos são dispersas por animais. A predominância dessa síndrome de dispersão no estrato arbóreo também foi mencionada por Gasparini Júnior (2004) para esta mesma floresta. Portanto, cabe destacar a importância desta síndrome na formação do banco de sementes do solo do trecho estudado a partir das matrizes localizadas no fragmento florestal, garantindo sua resiliência a distúrbios localizados como o fogo que foi aplicado.

\section{CONCLUSÕES}

A densidade do banco de sementes do solo do trecho estudado foi similar aos valores obtidos em outros estudos realizados em Floresta Estacional Semidecidual e a sua redução, após o fogo, não alterou de forma significativa a sua composição florística.

O conjunto de resultados obtidos com redução na densidade total de sementes germinadas, mas com respostas diferenciadas entre as espécies, indica que o tempo de duração de duas horas juntamente com a intensidade do fogo, podem ter sido letais para determinadas sementes de espécies mais sensíveis e/ou cujas sementes estavam depositadas mais superficialmente no solo, mas indiferente ou até favorável à germinação de sementes mais resistentes e/ou enterradas em maiores profundidades.

Como espécies arbóreas pioneiras, são responsáveis pela regeneração florestal após distúrbios naturais ou antrópicos, os maiores valores de densidade e riqueza de espécies deste grupo, encontrados após o uso do fogo, em comparação com as outras formas de vida e grupos ecológicos, indicam a resiliência deste trecho de floresta através da germinação de sementes presentes no solo.

A predominância de espécies zoocóricas no banco de sementes confirma a importância desta síndrome de dispersão na manutenção de populações de plantas em ecossistemas florestais, contribuindo para a regeneração dos mesmos frente a distúrbios como o fogo.

\section{AGRADECIMENTOS}

Os autores agradecem ao CNPq pela bolsa de Doutorado de V.L. de Camargos e de Produtividade em Pesquisa de S.V. Martins.

\section{REFERÊNCIAS BIBLIOGRÁFICAS}

\section{APG III (ANGIOSPERM PHYLOGENY} GROUP). An update of the Angiosperm Phylogeny Group classification for orders and families of flowering plants: APG III. Botanical Journal of the Linnean Society, Londres, v. 161, p. 105-121, 2009. ARAÚJO, M. M. et al. Densidade e composição florística do banco de sementes do solo de florestas sucessionais na região do Baixo Rio Guamá, Amazônia Oriental. Scientia Florestalis, Piracicaba, v. 59, p. 115-130, 2001.

BAIDER, C.; TABARELLI, M.; MANTOVANI, $\mathrm{W}$. The soil seed bank of a tropical montane forest, Brazil. Revista Brasileira de Biologia, São Carlos, v. 59, n. 2, p .319-328, 1999.

BASKIN, C. C.; BASKIN, J. M. Seeds. Ecology, biogeography, and evolution of dormancy and germination. San Diego: Academic Press, 1998. $666 \mathrm{p}$.

BATISTA NETO, J. P. et al. Banco de sementes do solo de uma Floresta Estacional Semidecidual, em Viçosa, Minas Gerais. Ciência Florestal, Santa Maria, v. 17, n. 4, p. 311-320, 2007.

BEADLE, N. C. W. Soil temperatures during forest fires and their effect on the survival of vegetation. Journal of Ecology, Londres, v. 28, p. 180-192, 1940.

BUDOWSKI, G. Distribution of tropical American rain forest species in the light of successional processes. Turrialba, San Domingos, v.15, n. 1, p.40-42, 1965.

CARMONA, R. Problemática e manejo de bancos de sementes de invasoras em solos agrícolas. Planta Daninha, Viçosa, v. 10, p. 5-16, 1992.

CASTELlANI, T. T.; STUBBLEBINE, W. H. Sucessão secundária inicial em mata tropical mesófila após perturbação por fogo. Revista Brasileira de Botânica, São Paulo, v. 16, n. 2, p. 181-203, 1993. CASTRO, P. S. et al. Interceptação da chuva por mata natural secundária na região de Viçosa - MG. Revista Árvore, Viçosa, v. 7, p. 76-89, 1983. 
CORREA, G. F. Modelo de evolução e mineralogia da fração argila de solos do Planalto de Viçosa, MG. 1984. 87 f. Dissertação (Mestrado em Solos e Nutrição de Plantas) - Universidade Federal de Viçosa, 1984.

COUTINHO, L .M. Fire in the ecology of the Brazilian cerrado. In: GOLDAMMER, J. G. (Ed.). Fire in the tropical biota - Ecosystem process and global challenge. Berlim: Springer-Verlag, 1990, p. $82-105$.

COUTINHO, L. M. O conceito de cerrado. Revista Brasileira de Botânica, São Paulo, v. 1, p. 17-23, 1978.

DALLING, J. W.; SWAINE, M. D.; GARWOOD, N .C. Dispersal patterns and seed bank dynamics of pionner trees in moist tropical forest. Ecology, Washington, v. 79, p. 564-578, 1998.

DALLING, J. W; SWAINE, M. D.; GARWOOD, N. C. Soil seed bank community dynamics in seasonally moist lowland forest, Panama. Journal of Tropical Ecology, Cambridge, v. 13, p. 659-680, 1997.

FENNER, M.; THOMPSON K. The ecology of seeds. Cambridge: Cambridge University Press, 2005. $250 \mathrm{p}$.

FERRANDIS, P.; HERRANZ, J. M. Response to fire of a predominantly transient seed bank in Mediterranean weedy pasture (eastern-central Spain). Ecoscience, Quebec, v. 8, n. 2, p. 211-219, 2001.

FERRANDIS, P.; HERRANZ, J. M. Soil seed bank response to fire in Mediterranean-Basin ecosystems. Recent Research in Developmental and Environmental Biology, Trivandrum, v. 1, p. 123-151, 2004.

FERRANDIS, P.; HERRANZ, J. M.; MARTÍNEZSÁNCHEZ, J. J. Effect of fire on hard-coated Cistaceae seed banks and its influence on techniques for quantifying seed banks. Plant Ecology, Amsterdan, v. 144, p. 103-114, 1999.

FRANCO, B. K. S. Análise do banco de sementes e da regeneração natural em um trecho de Floresta Estacional Semidecidual no Campus da Universidade Federal de Viçosa, MG. 2005. 72 f. Dissertação (Mestrado em Ciência Florestal) Universidade Federal de Viçosa, Viçosa, 2005.

GANDOLFI, S. História natural de uma Floresta Estacional Semidecidual no município de Campinas (São Paulo, Brasil). 2000. 551 f. Tese (Doutorado em Biologia Vegetal) - Universidade Estadual de Campinas, Campinas, 2000.

GANDOLFI， S.; LEITÃO FILHO, H. F.; BEZERRA, C. L. F. Estudo florístico e caráter sucessional das espécies arbustivo-arbóreas de uma floresta mesófila semidecidual no município de Guarulhos, SP. Revista Brasileira de Biologia, São Paulo, v. 55, n. 4, p. 753-767, 1995.

GARWOOD, N. C., Tropical soil seed banks: a review. In: LECK, M. A.; PARKER V. T.; SIMPSON R. L. (Eds.) Ecology of soil seed banks. San Diego: Academic Press, 1989, p. 149-209.

GASPARINI JÚNIOR, A. J. Estrutura e dinâmica de um fragmento de floresta estacional semidecidual no campus da Universidade Federal de Viçosa - Viçosa (MG). 2004, 55 f. Dissertação (Mestrado em Botânica) - Universidade Federal de Viçosa, Viçosa, 2004.

GOLFARI, L. Zoneamento ecológico do estado de Minas Gerais para reflorestamento. Belo Horizonte: PRODEPEF/PNUD/FAO/IBDF, 1975. 65 p. (Série técnica; 3 ).

GREIG, N. Regeneration mode in neotropical Piper: habitat and species comparisons. Ecology, New York, v. 74, p. 2125-2135, 1993.

GROMBONE-GUARATINI, M. T.; RODRIGUES, R. R. Seed bank and seed rain in a seasonal semideciduous forest in south-eastern Brazil. Journal of Tropical Ecology, Cambridge, v. 18, p. 759-774, 2002.

HOPKINS, M. S.; TRACEY, J. G.; GRAHAM, A. W. The size and composition of soil seed banks in remmant patches of three structural rainforest types in North Queensland, Australia. Australian Journal of Ecology, Canberra, v. 15, n. 1, p. 43-50, 1990.

HOWE, H. F.; SMALLWOOD, J. Ecology of seed dispersal. Annual Review of Ecology and Systematics, Palo Alto, v. 13, p. 201-228, 1982.

KENNARD, D. K. et al. Effects of disturbance intensity on regeneration mechanism in a tropical dry forest. Forest Ecology and Management, Amsterdam, v. 162, n. 2, p. 197-208, 2002.

KLEIN, R. M. Ecologia da flora e vegetação do Vale do Itajaí. Sellowia, Itajaí, v. 32, p. 165-389, 1980.

LORENZI, H. Árvores brasileiras: Manual de identificação e cultivo de plantas arbóreas nativas do Brasil. Nova Odessa: Plantarum, 1992. 352 p. v. 1.

MAROD, D. et. al. The effects of drought and fire on seed and seedling dynamics in a tropical seasonal Forest in Thailand. Plant Ecology, Amsterdam, v. 191, p. 41-57, 2002.

MARTINS, S. V. et al. Banco de sementes como indicador de restauração de uma área degradada por mineração de caulim em Brás Pires, MG. Revista 
Árvore, Viçosa, v. 32, n. 6, p. 1081-1088, 2008. MARTINS, S. V. et al. Regeneração pós-fogo em um fragmento de Floresta Estacional Semidecidual no município de Viçosa, MG. Ciência Florestal, Santa Maria, v. 12, n. 1, p. 11-19, 2002.

MARTINS, S. V. Soil seed bank as indicator of forest regeneration potential in canopy gaps of a semideciduous forest in Southeastern Brazil. In: FOURNIER, M V (Ed.) Forest regeneration: ecology, management and economics. New York, Nova Science Publishers, 2009. p. 34-58.

MELO, A. C. G.; DURIGAN, G.; GORENSTEIN, M. R. Efeitos do fogo sobre o banco de sementes em faixa de borda de Floresta Estacional Semidecidual, SP, Brasil. Acta Botânica Brasília, São Paulo, v. 21, n. 4, p.927-934, 2007.

METCALFE, D. J.; TURNER, I. M. Soil seed bank from lowland rain Forest in Singapore: canopygap and litter-gap demanders. Journal of Tropical Ecology, Cambridge, v. 14, p. 103-108, 1998.

MUELLER-DOMBOIS, D.; ELLENBERG, $\mathrm{H}$. Aims and methods of vegetation ecology. New York: John Wiley e Sons, 1974. 547 p.

OLIVEIRA-FILHO, A. T.; RATTER, J. A. Vegetation physiognomies and woody flora of the Cerrado Biome. In: OLIVEIRA, P. S.; MARQUIS, R. J. (Eds.) The Cerrado of Brazil: ecology and natural history of a Neotropical savana. New York: Columbia University Press, 2002, p. 91-120.

PAULA, A. et al. Alterações florísticas ocorridas num período de quatorze anos na vegetação arbórea de uma floresta estacional semidecidual em Viçosa - MG. Revista Árvore, Viçosa, v. 26, n. 6, p. 743749, 2002.

PENHALBER, E. F.; MANTOVANI, W. Floração e chuva de sementes em mata secundária em São Paulo, SP. Revista Brasileira de Botânica, São Paulo, v. 20, p. 205-220, 1997.

PIVELLO, V. R. et al. Chuva de sementes em fragmentos de Floresta Atlântica (São Paulo, SP, Brasil), sob diferentes situações de conectividade, estrutura florestal e proximidade da borda. Acta Botânica Brasílica, São Paulo, v. 20, n. 4, p. 845859, 2006.

PUTZ, F. E. Treefall pits and mounds, buried seeds, and the importance of soil disturbance to pioneer trees on Barro Colorado Island, Panama. Ecology, New York, v. 64, n. 5, p. 1069-1074, 1983.

RODRIGUES, R. R.; MARTINS, S. V.; MATTHES, L. H. F. Post-fire regeneration in a semideciduous mesophytic forest, south-easthern Brazil. In: BURK, A. R. (Ed.). New research on forest ecosystems.
New York: Nova Sciense Publishers, 2005, p. 1-19. SALDARRIAGA, J. G.; UHL,C. Recovery of forest vegetation following slash-and-burn agriculture in the upper rio Negro. In: GOMEZ-POMPA, A.; WHITMORE, T. C.; HADLEY, M. (Eds.). Tropical rain forest: regeneration and management. New York: Blackwell, 1991, p. 303-312.

SILVA, V. F. et al. Impacto do fogo no componente arbóreo de uma floresta estacional semidecídua no município de Ibituruna, MG, Brasil. Acta Botânica Brasílica, São Paulo, v. 19, n. 4, p. 701-716, 2005. SILVA-MATOS, D. M.; FONSECA, G. D. F. M.; SILVA-LIMA, L. Differences on post-fire regeneration of the pioneer trees Cecropia glazioui and Trema micrantha in a lowland Brazilian Atlantic Forest. Revista de Biología Tropical, San José, v. 53, n. 1-2, p. 1-4, 2005.

SIMPSON, R. L; LECK, M. A.; PARKER, V. T. Ecology of soil seed banks. California: Academic Press, 1989. $385 \mathrm{p}$.

SOUZA, P. A. Efeito da sazonalidade da serapilheira sobre o banco de sementes visando seu uso na recuperação de áreas degradadas. 2003, 130 f. Tese (Doutorado em Ciência Florestal) - Universidade Federal de Viçosa, Viçosa, 2003.

STILES, E. G.; ROSSELLI, L. Comsumption of fruits of the Melastomataceae: how diffuse is coevolution. Vegetatio, Amsterdam, v. 107-108, p. 57-73. 1993.

UHL, C. et al. Successional patterns associated with slash-and-burn agriculture in the upper Rio Negro of the Amazon Basin. Biotropica, Zurich, v. 14, n. 4, p. 249-254, 1982.

UHL, C. Factors controlling succession following slash-and-burn agriculture in Amazonia. Journal of Ecology, Londres, v. 75, p. 377-407, 1987.

UHL, C.; CLARK, K.; MAUIRINO, P. Vegetation dynamics in Amazonian treefall gaps. Ecology, New York, v. 69, p. 751- 763, 1988.

VAN DER PIJL, L. Principles of dispersal in higher plants. 3. ed. Berlin: Springer-Berlag, 1982. VELOSO, H. P.; HANGEL-FILHO,A. L. R.; LIMA,J. C. Classificação da vegetação brasileira, adaptada a um sistema universal. Rio de Janeiro: IBGE, 1991. $124 \mathrm{p}$

WILLIAMS, P. R. et al. Germinable soil seed banks in a tropical savanna: seasonal dynamics and effects of fire. Austral Ecology, Adelaide, v. 30, p. 79-90, 2005.

WRIGHT, H. A.; BAILEY, A. W. Fire Ecology : United States and Canada. New York: John Wiley e Sons, Inc. 1982, 501 p. 